\title{
Schmickler, Wolfgang; Santos, Elizabeth: Interfacial Electrochemistry, 2nd ed.
}

\author{
2010, XIV + 272 p., \$79.95; ISBN: 978-3-642-04936-1
}

\author{
Rudolf Holze
}

Received: 20 December 2010 / Accepted: 20 December 2010 /Published online: 22 January 2011

(C) Springer-Verlag 2011

To start the introduction of the second edition of a book on current electrochemistry with pictures of a device allegedly used by the Parthans for electroplating around 250 B.C. and to overlook generously the heated debate and numerous speculations about this archeological find is surprising at best, presumably it is counterproductive because it puts electrochemistry in a somewhat strange light. Fortunately, the historic excursion-which apparently did not serve any particular purpose-stops with Volta and Galvani, and most fortunately there are more helpful histories of electrochemistry available elsewhere (P. Kurzweil in: Encyclopedia of Electrochemical Power Sources Vol. 3 (J. Garche, C.K. Dyer, P.T. Moseley, Z. Ogumi, D.A.J. Rand, B. Scrosati, Eds.), Elsevier, Amsterdam 2009, p. 533).

A few lines down, the authors move into safer areas: They define the subject of their book as the study of structures and processes at interfaces between electronic and ionic conductors (the electrified interface or electrodics as termed by Bockris and Reddy in separating this part of science from electrolytics). The novice in the field assuming that he might be holding a systematically organized textbook will be hoping at the end of the first chapter (out of 20) to get an overview about what is coming-without success. Instead, he is offered in the following 19 chapters of wildly varying length and width a somewhat arbitrary collection of contributions ranging

R. Holze $(\bowtie)$

Chemnitz University of Technology,

Chemnitz, Germany

e-mail: Rudolf.holze@chemie.tu-chemnitz.de from "Inner sphere and ion-transfer reactions" over "Metal deposition and dissolution" to "Convection techniques"- the reviewers selection is arbitrary and coincidental. Presumably the history of the book is in part reason of this mix. It was initially written as a treatment of electrochemical interfaces from the point of view of a theoretician. It was certainly a valuable contribution because at the time of publication most textbooks were written from the thermodynamic or experimental point of view. Extended treatment of experimental methods in the second edition may have ended in a more complete textbook of interfacial electrochemistry, but instead the authors decided-as explained in the preface-to keep non-traditional methods (presumably spectroelectrochemical ones) out of the second edition. Instead, a chapter on "Experimental techniques for electrode kinetics-nonstationary methods" has been added, and as an addition (presumably because the techniques are considered to be stationary ones) a small chapter on "Convection techniques." Nothing on experimental techniques-even traditional ones-applied in studies of double layer structure. This appears arbitrary, and the reader looking for an introductory overview will end up with a rather skewed picture. About the reasons for this choice speculation may be permitted, and a look into the publication record, especially of the newly added coauthor, helps. Almost exclusively, methods amply employed in the authors' lab are covered only. Selective referencing tilted towards sources somewhat hard to get does not cover this preference entirely.

Thus, the question for aim and purpose of the book remains: It may be of limited help as an introductory text, and as a reference book it lacks a systematic approach and 
completeness. Most likely it will be "additional" reading for graduate students.

The book is carefully prepared and generously illustrated. Only, in a few cases, a little more attention should have been devoted to layout, but this never seriously impedes the purpose of a figure. This book is a welcome addition to every library of an institution and to the personal library of surface scientists and - of course - of electrochemists. Its price places it even in the range of the postgraduate student. The somewhat diffuse concept and limited width of subjects will keep the book from becoming a standard textbook of electrochemistry. 